\title{
Review: prompt endoscopy is not a cost effective strategy for initial management of dyspepsia
}

Ford AC, Qume M, Moayyedi P, et al. Helicobacter pylori "test and treat" or endoscopy for managing dyspepsia: an individual patient data meta-analysis. Gastroenterology 2005;128:1838-44.

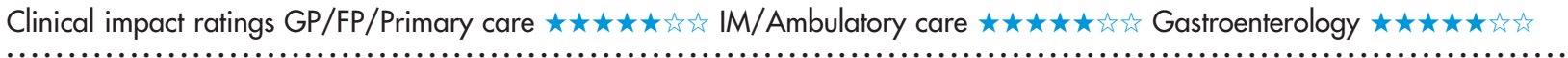

In patients with dyspepsia, how cost effective is initial management with prompt endoscopy compared with a test and treat approach for inducing resolution of symptoms?

\section{METHODS}

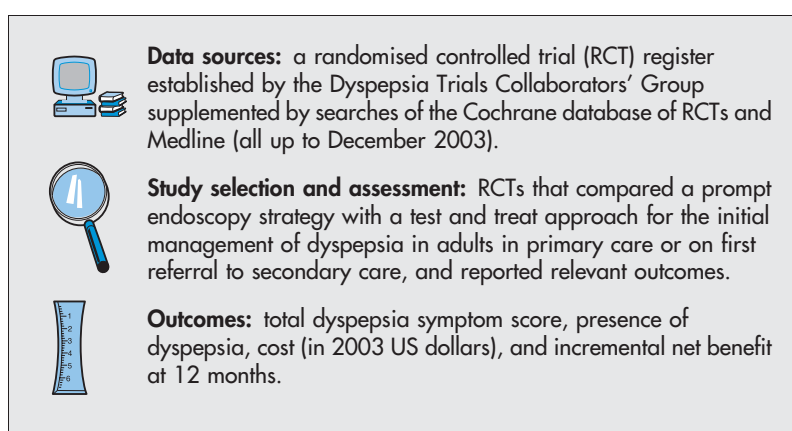

\section{MAIN RESULTS}

5 RCTs $(\mathrm{n}=1924)$ (mean age 41 years, 50\% men) met the selection criteria. Effects of the intervention on dyspepsia symptoms were pooled using meta-analysis of individual patient data. The groups did not differ for total dyspepsia symptom scores (table). However, fewer persons in the endoscopy group than in the test and treat group still had symptoms of dyspepsia at 12 months (table). Mean total cost per patient was greater in the endoscopy group than in the test and treat group (table). At a willingness to pay of $\$ 1000$ per patient who is free of dyspepsia symptoms, the incremental net benefit was lower in the endoscopy group than in the test and treat group. Prompt endoscopy became cost effective only when the willingness to pay per patient who is symptom free was increased to $\$ 180000$.

\section{CONCLUSION}

In patients with dyspepsia, initial management with prompt endoscopy is slightly more effective but not cost effective compared with a test and treat approach for inducing resolution of symptoms.

Abstract and commentary also appear in ACP Journal Club.

For correspondence: Professor B C Delaney, University of Birmingham Birmingham, UK. b.c.Delaney@bham.ac.uk

Source of funding: Primary Care Research Trust for Birmingham and Midlands Research Practices Consortium.

\section{Commentary}

The management of dyspepsia remains controversial although the most recent US guidelines continue to recommend $H$ pylori test and treat over prompt endoscopy in patients without alarm features. ${ }^{12}$ Ford et al provide the first individual patient data meta-analysis of 5 management trials (2 of which remain unpublished in full). Using individual patient data removed the issue of heterogeneity that confounds the interpretation of many meta-analyses. The results robustly support a test and treat strategy in terms of cost effectiveness, even though the cost for endoscopy used in the model was low $(\$ 450)$. It seems that fewer endoscopies in the test and treat group and increased proton pump inhibitor consumption in the prompt endoscopy group may drive the cost differences. While willingness to pay for becoming free of dyspepsia is arguably an artificial construct, in terms of combining data this represents a clinically interpretable end point.

It is notable that the rate of symptom resolution was significantly greater in the endoscopy group than in the test and treat group, although the difference was small and arguably not clinically relevant. However, it is unclear why endoscopy should have any additional benefit. A weakness is that US cost data were applied, but none of the studies were done in the US

The $H$ pylori test and treat strategy was equally good in those with predominant epigastric pain or heartburn, suggesting that distinguishing management of dyspepsia from gastroesophageal reflux disease may be somewhat artificial. ${ }^{3}$ While this analysis cannot capture other dimensions of prompt endoscopy that may be of value, including reassurance to patient and physician, overall, test and treat should remain the standard of care for management of uninvestigated dyspepsia.

\section{Nicholas J Talley, MD, PhD Mayo Clinic \\ Rochester, Minnesota, USA}

1 Talley NJ, Moayyedi P, Vakil N. AGA Technical Review: evaluation of dyspepsia. Gastroenterology 2005 (in press).

2 Talley NJ, Vakil N. Guidelines for the management of dyspepsia. Am J Gastroenterol 2005; 100:2324-37.

3 DeVault KR, Castell DO. Updated guidelines for the diagnosis and treatment of gastroesophageal reflux disease. Am J Gastroenterol 2005;100:190200.

Initial management with prompt endoscopy $v$ test and treat in patients with dyspepsia at 12 months

\begin{tabular}{ll}
\hline Outcomes & Standardised mean difference $(95 \% \mathrm{Cl})$ \\
\hline Total dyspepsia symptom scores & $-0.11(-0.28$ to 0.07$)$ \\
\hline & RRR (CI) \\
\hline Presence of symptoms & $5 \%$ (1 to 8$) \dagger$ \\
\hline & Weighted mean difference (CI) \\
\hline Additional cost/patient of prompt endoscopy (2003 US dollars) & $\$ 389$ (276 to 502) $\neq$ \\
\hline
\end{tabular}

*RRR and $\mathrm{Cl}$ defined in glossary.

†Significant difference favours prompt endoscopy.

‡Significant differences favour test and treat. 